Trivent Publishing

(C) The Authors, 2016

Available online at http://trivent-publishing.eu/

Series: Engineering and Industry

Volume: Watershed and River Basin Management

\title{
Pollution State and Modeling of Organophosphoric Acid Triesters in the Yamato River Basin
}

\author{
H. Shimazu \\ School of Science \& Engineering, Kinki University \\ 3-4-1 Kowakae, Higashiosaka, Osaka 577-8502, Japan, hshimazu@civileng.kindai.ac.jp
}

\begin{abstract}
The concentrations of organophosphoric acid triesters (OPEs) in the Yamato River basin were investigated and numerically simulated in this study. The Yamato River is one of the biggest in the Kansai District, Japan. The basin length, area and sewer coverage are $68 \mathrm{~km}, 1070 \mathrm{~km}^{2}$, and $70 \%$, respectively. Seven kinds of OPEs were measured at the eight sampling locations of the Yamato River and its tributaries from November to December 2006. All of the OPEs were detected and the ranges of concentrations were from 0.0018 to $5.6 \mu \mathrm{g} / \mathrm{L}$. The detection rates were also high, from $69 \%$ to $100 \%$. It was reported that the domestic wastewater and the sewage wastewater were the dominant OPE pollution sources. Using the pollution data of a few kinds of wastewater treatment types in a number of sub-basins, per-capita effluent values on OPEs and water discharge, the base flow rates, and the OPE diminishing rates, a model was developed for predicting OPE concentrations in the Yamato River basin. Then, it was confirmed that the differences between the observed and predicted OPES were within one order of magnitude in almost all cases.
\end{abstract}

\section{Keywords}

Aquatic environmental behavior; organophosphoric acid triesters; prediction model; the Yamato River

This is an Open Access article distributed in accordance with the Creative Commons Attribution Non Commercial (CC-BYNC-ND 4.0) license, which permits others to copy or share the article, provided original work is properly cited and that this is not done for commercial purposes. Users may not remix, transform, or build upon the material and may not distribute the modified material (http://creativecommons.org/licenses/by-nc/4.0/) 


\section{Introduction}

More than 30 million chemicals are considered to be present in the world. Some of them have been causes of many kinds of environmental pollution and destruction. There is an increasing public concern for the environmental fate of organic pollutants these days. Organophosphoric acid triesters (OPEs) are a group of environmental pollutants, and some of them are known to be mutagenic and carcinogenic. OPEs have been of concern because some of them are frequently detected in the aquatic environment. The purpose of this paper is to examine the OPEs in the Yamato River basin which is one of the biggest in the Kansai District, Japan. A few models for predicting chemicals in the environment have been reported by Mackay and Paterson (1981), and Morioka and Tokai (1987) etc. However, little is known about the prediction model and further refinement is needed. This paper proposes an accurate model to predict OPEs.

\section{Methods}

\section{A. Sampling location}

Figure 1 shows the Yamato River basin and sampling locations. The Yamato River is one of the biggest rivers in the Kansai District, Japan. The basin length, area, and population are $68 \mathrm{~km}$, $1,070 \mathrm{~km}^{2}$, and 2,500,000, respectively. The percentage of sewered population in the basin is $70.4 \%$.

The samples were taken at eight locations in the Yamato River basin from November to December 2006. The first and second locations were around the source of the Yamato River. The third and fourth locations were around the midstream of the Yamato River and their upper populations are approximately 500,000 and 1,200,000. The fifth location was near the joint with the Ishi River and the upper population is about $1,800,000$. The sixth location was about $5 \mathrm{~km}$ before the Osaka Bay. The seventh and eighth locations were at the mouth of the Ishi River and Nishiyoke River. Both upstream populations are approximately 400,000.

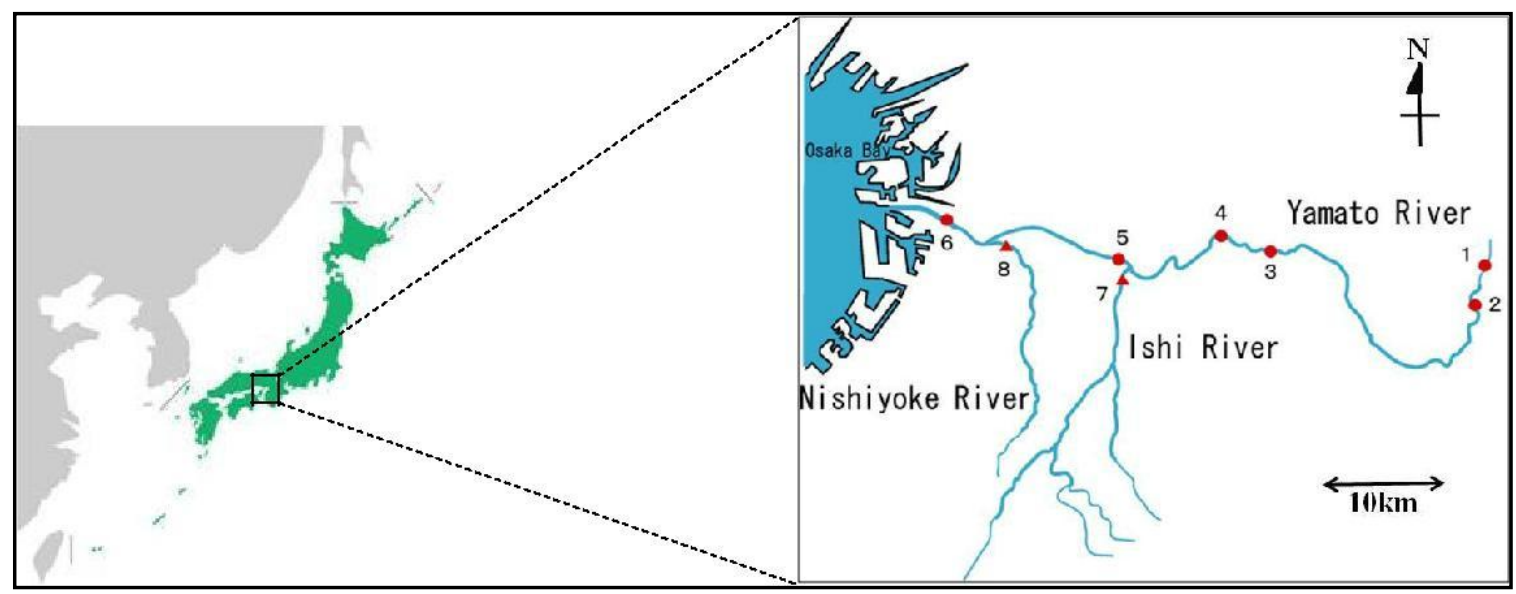

Fig. 1. Sampling locations in the Yamato River basin 


\section{B. OPE analytical method}

OPEs measured in this study were tributhyl phosphate (TBP), tri-2-butoxyethyl phosphate (TBXP), tri-2-chloroethyl phosphate (TCEP), tris(2-ethylhexyl) phosphate (THEP), triethyl phosphate (TEP), trimethyl phosphate (TMP), and triphenyl phosphate (TPP).

$1000 \mathrm{ml}$ samples were filtered with Whatman GF/C. Then the aliquots for the dissolved OPEs were gone through Waters Sep-Pak PS-2 by means of a concentrator, and the dissolved OPEs were extracted with $5 \mathrm{ml}$ dichloromethane phases. The phases were taken into 5 -ml glass receivers and concentrated to $2 \mathrm{ml}$. They were analyzed on a gas chromatograph with mass spectrometer detection system.

Table 1. Analytical conditions in GC/MS

\begin{tabular}{|c|c|c|}
\hline \multicolumn{3}{|c|}{ Separation column: $\mathrm{HP}-5 \mathrm{MS}(30 \mathrm{~m} \times 0.25 \mathrm{~mm} \times 0.25 \mu \mathrm{m})$} \\
\hline Injection temperature: $250^{\circ} \mathrm{C}$ & Injection method: Splitless & Injection quantity: $2 \mu \mathrm{L}$ \\
\hline \multicolumn{3}{|c|}{ Oven temperature program: $70^{\circ} \mathrm{C}(1.5 \mathrm{~min}) \rightarrow+20^{\circ} \mathrm{C} / \mathrm{min} \rightarrow 180^{\circ} \mathrm{C} \rightarrow+5^{\circ} \mathrm{C} / \mathrm{min} \rightarrow 280^{\circ} \mathrm{C}(1 \mathrm{~min})$} \\
\hline Selected ions: $99,110,125,249,326$ & Detector temperature: $230^{\circ} \mathrm{C}$ & Carrier gas: Helium \\
\hline
\end{tabular}

\section{OPE prediction model}

It has been reported that houses, sewage treatment plants, disposal sites, factories, etc. are the dominant OPE pollution sources from previous studies (Ishikawa, 1985; Kawagoshi, 1997). In this study, the pollution sources are considered to be houses, sewage treatment plants, and factories. The disposal sites were not taken into account as pollution source because there were few disposal sites that were close to the Yamato River basin. In order to predict OPE concentrations in the Yamato River basin, we developed a model as follows:

OPE concentration $=$ (discharge loads from OPE pollution sources $/$ flow rate at the predicted location $)$ $\times \exp (-$ OPE diminishing rate in the river $\times$ OPE residence time in the river)

Discharge loads from OPE pollution sources are equal to the total amount of unit discharge loads from houses, sewage treatment plants, and factories. The OPE discharge loads from houses are calculated from multiplying the per-capita effluent OPE values of unsewered wastewater by the unsewered population data above prediction locations. The OPE discharge loads from sewage treatment plants are calculated from multiplying the per-capita effluent OPE values of sewage wastewater by the sewered population data above prediction locations. The per-capita effluent values ( $\mu \mathrm{g} / \mathrm{person} /$ day) of OPEs are shown in Shimazu (2002).

The OPE discharge loads from factories are calculated from (unit discharge concentration) $\times$ (discharge rate from factories) $\times$ (residual efficiency). The unit discharge concentration $(\mu \mathrm{g} / \mathrm{L})$ of TBP and TCEP are 0.011 and 0.125 from the geometric medians of OPE concentrations from many kinds of factories (Ishikawa, 1985). The unit discharge concentration $(\mu \mathrm{g} / \mathrm{L})$ of TBXP and TEP are 0.006 and 0.00085 from half the limit of detection (Table 2). The discharge rates (L/day) from factories were calculated from the total water consumption for industries minus the water consumption for industrial boiler, cooling, and warming. The residual efficiencies are calculated from the per-capita 
effluent OPE values from sewage wastewater divided by the per-capita effluent OPE values from unsewered wastewater. The diminishing rates (1/day) in the river of OPEs are shown in Shimazu (2002).

The daily flow rates (L/day) at location $1,2,7$, and 8 were calculated from multiplying the measured cross section by the measured flow rate. The rates at the rest locations were predicted by the relationship between flow rate and water level from the measured data by Japanese Ministry of Land, Infrastructure, Transport and Tourism (2007). Figure 2 shows the relationship between flow rate and water level at location 3 .

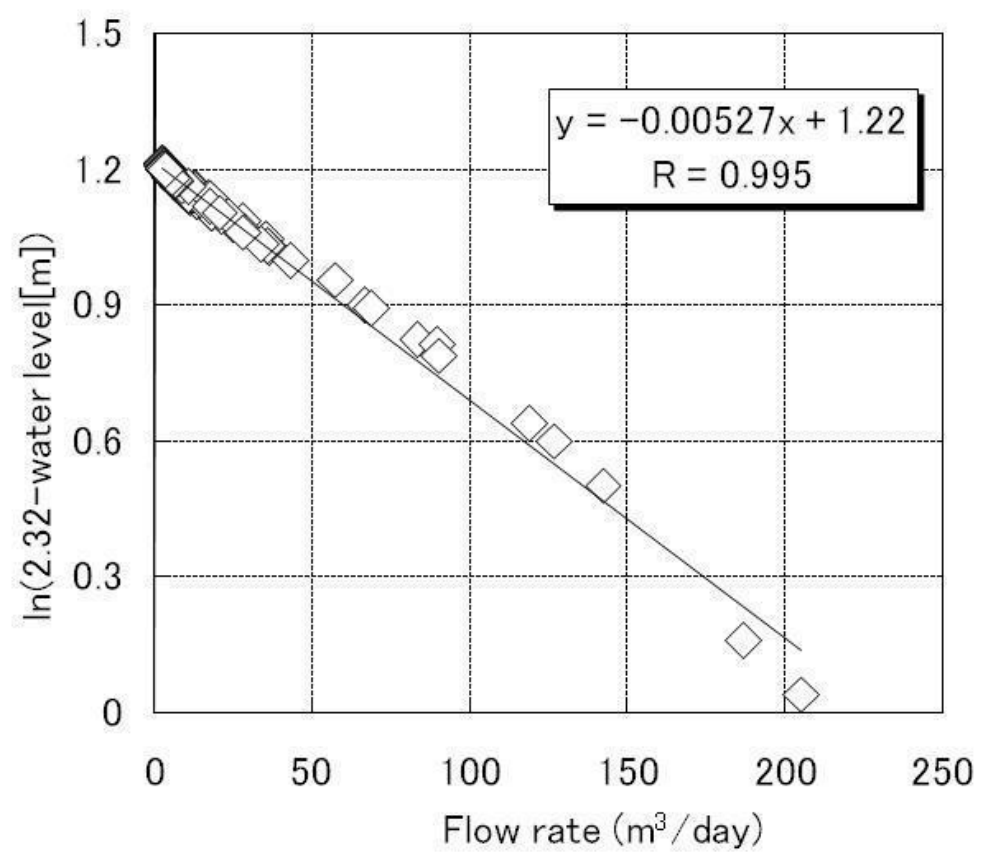

Fig. 2. Flow rate vs. water level at location 3

\section{Results and discussion}

Measured OPE concentrations are summarized in Table 2. The median concentrations of TBXP, TEHP, TMP and TPP were calculated after removing detection limit data. TBP, TCEP and TEP were detected at all locations on every measurement. Other OPEs were also detected at most of the locations frequently. The median concentration on TEHP and TMP were $0.0046 \mu \mathrm{g} / \mathrm{L}$ and $0.66 \mu \mathrm{g} / \mathrm{L}$. The detected concentrations were different for each of the OPEs, and the difference between TEHP and TMP was about two orders of magnitude. Japanese Ministry of the Environment (2007) has reported that the concentration ranges on some OPEs in Japan are $0.01-1 \mu \mathrm{g} / \mathrm{L}$ order of magnitude. The detected concentrations were very similar to those values. 
Table 2. Measured OPE concentrations in the Yamato River basin $\quad[\mu \mathrm{g} / \mathrm{L}]$

\begin{tabular}{|c|c|c|c|c|c|c|c|c|c|c|c|c|c|}
\hline & \multirow{3}{*}{$\mathbf{d} / \mathbf{m} / \mathbf{y}$} & \multirow{3}{*}{$\begin{array}{c}\text { Detectio } \\
\mathbf{n} \\
\text { limit }\end{array}$} & \multicolumn{8}{|c|}{ Location No. } & \multirow{3}{*}{\begin{tabular}{|l} 
Median \\
$1-8$ \\
\end{tabular}} & \multirow{2}{*}{\multicolumn{2}{|c|}{ Detection rate }} \\
\hline & & & \multicolumn{6}{|c|}{ Yamato River } & \multicolumn{2}{|c|}{ Tributary } & & & \\
\hline & & & 1 & 2 & 3 & 4 & 5 & 6 & 7 & 8 & & $1-6$ & $7-8$ \\
\hline \multirow[b]{2}{*}{ ТВP } & $18 / 11 / 06$ & \multirow{2}{*}{0.00040} & 0.0073 & 0.0090 & 0.062 & 0.38 & 0.44 & 0.29 & 0.031 & 0.36 & \multirow[b]{2}{*}{0.052} & \multirow[b]{2}{*}{$12 / 12$} & \multirow[b]{2}{*}{$4 / 4$} \\
\hline & $09 / 12 / 06$ & & 0.0077 & 0.0022 & 0.042 & 0.26 & 0.097 & 0.064 & 0.015 & 0.038 & & & \\
\hline \multirow[b]{2}{*}{ TBXP } & $18 / 11 / 06$ & \multirow[b]{2}{*}{0.012} & 0.019 & 0.024 & 0.55 & 0.47 & 0.93 & 5.6 & 0.068 & 1.1 & \multirow[b]{2}{*}{0.22} & \multirow[b]{2}{*}{$11 / 12$} & \multirow[b]{2}{*}{$4 / 4$} \\
\hline & $09 / 12 / 06$ & & 0.056 & $<0.012$ & 0.59 & 0.29 & 0.027 & 0.18 & 0.059 & 0.22 & & & \\
\hline \multirow[b]{2}{*}{ TCEP } & 18/11/06 & \multirow[b]{2}{*}{0.0012} & 0.0094 & 0.013 & 0.17 & 0.41 & 0.79 & 1.5 & 0.044 & 0.84 & \multirow[b]{2}{*}{0.090} & \multirow[b]{2}{*}{$12 / 12$} & \multirow[b]{2}{*}{$4 / 4$} \\
\hline & 09/12/06 & & 0.018 & 0.0046 & 0.14 & 0.17 & 0.046 & 0.082 & 0.032 & 0.097 & & & \\
\hline \multirow[b]{2}{*}{ TEHP } & $18 / 11 / 06$ & \multirow[b]{2}{*}{0.0012} & 0.0040 & 0.0039 & 0.0057 & 0.0056 & 0.024 & 0.014 & 0.0049 & 0.0096 & \multirow[b]{2}{*}{0.0046} & \multirow[b]{2}{*}{$9 / 12$} & \multirow[b]{2}{*}{$3 / 4$} \\
\hline & 09/12/06 & & 0.0043 & $<0.0012$ & 0.0037 & 0.0039 & $<0.0012$ & $<0.0012$ & 0.0018 & $<0.0012$ & & & \\
\hline \multirow{2}{*}{ TEP } & $18 / 11 / 06$ & \multirow[b]{2}{*}{0.0017} & 0.19 & 0.27 & 0.38 & 0.54 & 1.1 & 1.3 & 0.34 & 0.90 & \multirow{2}{*}{0.23} & \multirow[b]{2}{*}{$12 / 12$} & \multirow[b]{2}{*}{$4 / 4$} \\
\hline & $09 / 12 / 06$ & & 0.11 & 0.18 & 0.26 & 0.12 & 0.11 & 0.067 & 0.050 & 0.075 & & & \\
\hline \multirow{2}{*}{ TMP } & $18 / 11 / 06$ & \multirow{2}{*}{0.0013} & 0.11 & 0.53 & 0.77 & 0.71 & 4.3 & 3.1 & 0.66 & 2.9 & & & \\
\hline & 09/12/06 & & 0.044 & $<0.0013$ & 0.13 & 0.013 & $<0.0013$ & $<0.0013$ & $<0.0013$ & $<0.0013$ & 0.66 & 9/12 & $2 / 4$ \\
\hline & $18 / 11 / 06$ & & 0.0030 & 0.0024 & 0.0042 & 0.0075 & 0.018 & 0.067 & 0.0060 & 0.020 & & & \\
\hline $1 P P$ & 09/12/06 & 0 & 0.0068 & $<0.0030$ & 0.041 & 0.037 & 0.0031 & 0.0057 & 0.0051 & $<0.0030$ & 0.0064 & $11 / 12$ & 1/4 \\
\hline
\end{tabular}

The concentrations at locations 1-8 are predicted by the OPE prediction model. The relationship between the logarithmic values of the observed OPEs and those of the predicted OPEs are shown in Fig 3. Although the absolute values of the differences between the logarithmic values of the observed OPEs and those of the predicted OPEs exceeded 1.0 once in the case of TBP and twice in the case of TCEP among 16 samples, the means of the differences between them for TBP and TCEP were only about 0.49 . The model is fairly useful for the prediction of TBP and TCEP. On the other hand, the absolute values of the differences between the logarithmic values of the observed OPEs and those of the predicted OPEs exceeded 1.0 five times in the case of TBXP among 15 samples and 11 times in the case of TEP among 16 samples. The means of the differences between them for TBXP and TEP were 0.86 and 1.3. Calculating the predicted TBXP, half the limit of detection in this report $(0.006 \mu \mathrm{g} / \mathrm{L})$ was used as the unit discharge concentration from factories. This is probably because the predicted TBXP values were higher than the observed TBXP values. The predicted TEP values were much lower than the observed TEP values because the other discharge factors like gas stations etc. could exist (Fukushima, 1996). Although there are problems with TBXP and TEP that need to be addressed, the differences between the predicted OPEs and observed OPEs are within one order of magnitude in 44 out of 63 samples. 

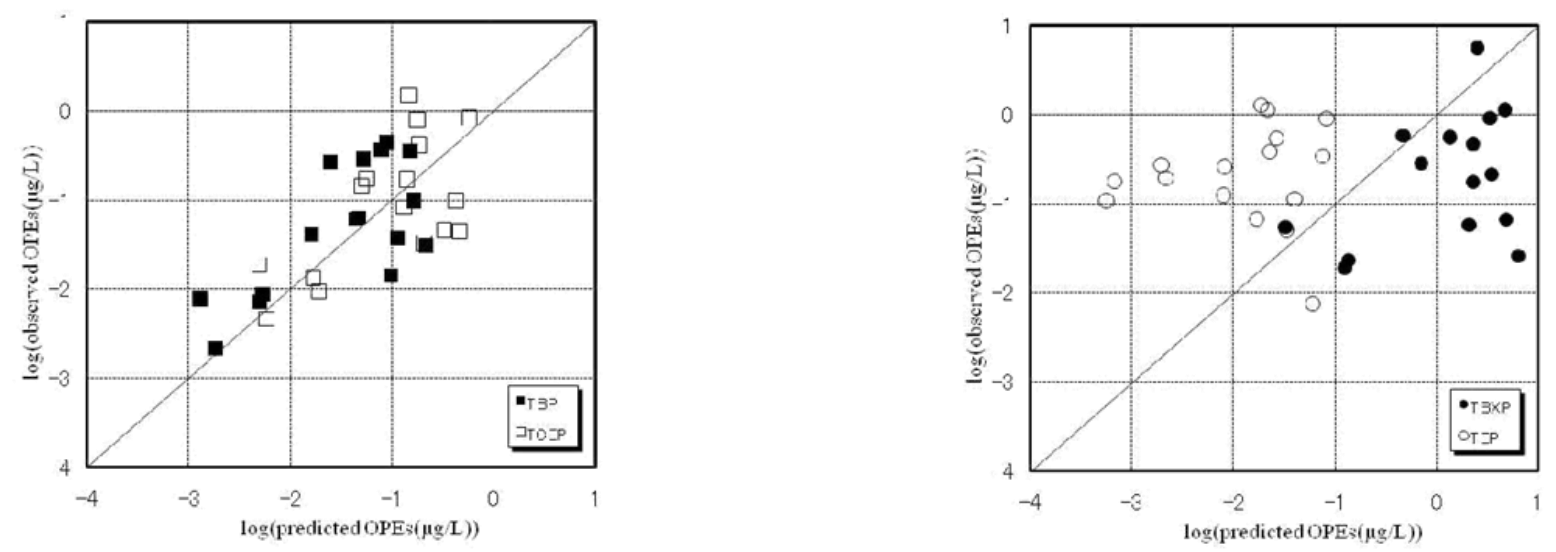

(a) In the case of TBP and TCEP (b) In the case of TBXP and TEP

Fig. 3 Relationships between the observed OPEs and the predicted OPEs

\section{Conclusions}

In this study, organophosphoric acid triesters (OPEs) were measured and numerically simulated in the Yamato River basin. Seven kinds of OPEs were measured at the eight sampling locations of the Yamato River and its tributaries from November to December 2006. TBP, TCEP and TEP were detected at all locations on every measurement. TBXP, TEHP, TMP, and TPP were also detected at most of the locations frequently. The median concentration on TEHP and TMP were $0.0046 \mu \mathrm{g} / \mathrm{L}$ and $0.66 \mu \mathrm{g} / \mathrm{L}$. The detected concentrations were different for each of the OPEs. An OPE prediction model in the Yamato River basin was developed using the pollution data of a few kinds of wastewater treatment types in a number of sub-basins, per-capita effluent values on OPEs and water discharge, the base flow rates, and the OPE diminishing rates. The model is fairly useful for the prediction of TBP and TCEP. On the other hand, there are problems with TBXP and TEP that need to be addressed. However, the differences between the observed OPEs and the predicted OPEs are within one order of magnitude in 44 out of 63 samples. It is hoped that this model will be helpful to predict OPEs at an arbitrary location in the Yamato River.

\section{References}

Ishikawa S., Shigezumi K., Yasuda K. and Shigemori N. (1985). Determination of organic phosphate esters in factory effluent and domestic effluent, J. Japan Society on Water Pollution, 8(8), 529-535.

Fukushima M. (1996). Behavior of organophosphoric acid triesters in aquatic environment, J. Japan Society on Water Environment, 19(9), 692-699.

Japanese Ministry of the Environment (2007). Chemicals in the Environment, Environment Health and Safety Division, Tokyo, Japan.

Japanese Ministry of Land, Infrastructure, Transport and Tourism (2007). Water Information System, National Land with Water Information Data Management Center, Tokyo, Japan.

Kawagoshi Y., Fujiwara Y., Fukunaga I., Itoh H. (1997) Change of organophosphoric acid triesters concentration at sea-based solid waste disposal site, J. Japan Society on Water Environment, 20(3), 166-174. Mackey D. and Paterson S. (1981). Calculating fugacity, Environ. Sci. Technol., 1(9), 1006-1014.

Morioka T. and Tokai A. (1987). Practical application of predictive fate models for chemical risk assessment, Proc. of Environ. \& Sani. Eng. Res., 23, 115-124. 
Shimazu H. (2002). Study on Predicting Environmental Fate of Chemicals and Risk Assessment based on the Prediction. phD thesis, Department of Civil and Environmental Engineering, Hiroshima University. 